Research Article

\title{
New Media Advertising Communication Analysis Model Based on Extension Neural Network
}

\author{
Zhe Zhang \\ School of Humanities and Law, North China University of Technology, Beijing 100144, China \\ Correspondence should be addressed to Zhe Zhang; zhangzhe@ncut.edu.cn
}

Received 15 November 2021; Revised 8 December 2021; Accepted 15 December 2021; Published 29 December 2021

Academic Editor: Le Sun

Copyright $\odot 2021$ Zhe Zhang. This is an open access article distributed under the Creative Commons Attribution License, which permits unrestricted use, distribution, and reproduction in any medium, provided the original work is properly cited.

In order to improve the effect of new media advertising communication analysis, this paper combines the scalable neural network to construct the new media advertising communication analysis model. Moreover, this paper analyzes in detail the basic theories of fuzzy neural network and extension evaluation, the structure design and learning algorithm, and classification of fuzzy neural network. In particular, this paper summarizes the optimization algorithms and methods of neural network structure. In addition, this paper improves the algorithm to meet the needs of new media advertising data analysis and builds an intelligent system framework. The experimental verification shows that the new media advertising communication analysis model based on the extension neural network proposed in this paper meets the new media advertising communication analysis effect.

\section{Introduction}

With the increasing innovation and popularization of Internet applications, a large number of information and people have gathered in the Internet time and space, and rich digital network media and applications have become an indispensable communication tool in public life. The new public attention points have formed a variety of new media, which show the characteristics of strong interaction, precise positioning, and topic segmentation [1]. From application tools to social and cultural carriers, the Internet is increasingly showing its media attributes. In particular, the emergence of the Internet, mobile phones, and a large number of new outdoor media has made the development of the "new media" industry prosperous. At present, rich media forms and rich media information surround the people's living space. For a time, the term "new media" has become a popular vocabulary familiar to the public. From the perspective of natural science or social science, the birth of "new media" is of great significance [2]. However, due to the surging development of the "new media" industry, new technological changes are coming. Due to the endless emergence of new media and new applications, as well as the impetuous mentality of media commercial applications, the theoretical community's understanding and research on "new media" has shown a multipolarity [3].

The process of digitization has brought about tremendous changes in the communication pattern and the media itself: not only have the information (computer) industry, telecommunications industry, and mass media industry presented a new trend of business intersection of triple play, but also cross-domain enterprises have emerged, with questions about mergers and acquisitions and integration. Digital media has changed the characteristics of mass communication in the past and enabled the characteristics of "focus" and "niche" to be carried forward. For example, digital media technology makes radio, television media, and scarce channel resources called rich resources [4]. Digital media has also changed the one-way media communication in the past. The status of the "audience" that can only passively receive information has been greatly changed, and the initiative of receiving information is increasingly shifted to the audience [5]. Digital media has changed the traditional feature that audiences must be synchronized when listening to and watching radio and television and has achieved asynchrony; that is, audiences can listen and watch at any time selected, and they can listen and watch repeatedly if they are interested [6]. Whether newspapers and 
periodicals are printed in different places through satellite transmission or distributed through the Internet, or digital satellite broadcasting and satellite TV, they are all characterized by covering intercontinental and even the world, pursuing international influence and competing for share in the international media market.

This thesis combines the scalable neural network to construct the new media advertising communication analysis model and conducts research on the new media advertising communication analysis.

\section{Related Work}

Some scholars combine changes in communication methods with technological updates and call new media "interactive digital composite media" [7]. Literature [8] provided a more comprehensive and objective summary of new media advertising. It believes that "new media advertising refers to the brand communication behavior and form that is reflected in the multimedia video based on digital transmission, which can realize instant interaction of information, and the terminal appears as a network link and is conducive to the communication of information between advertisers and target audiences." Literature [9] believed that new media advertising extends in the direction of "immediate, mobile, request, and concise." It collects, produces, processes, compresses, stores, and applies "advertising information" into various forms of advertising expression. Literature [10] believed that the forms of new media advertising mainly include outdoor new media, mobile new media, and mobile phone new media. Among them, outdoor new media include outdoor video, outdoor touch, and outdoor projection, etc., while mobile new media is realized through mobile TV, car TV, and subway TV. Literature [11] believed that homepage advertising occupies an important position in new media advertising. The reason is that homepage advertisements can not only spread the image and culture of the company, but also convey information about the company's products. Moreover, many companies have e-commerce platforms, so homepage advertisements play a direct role in the sales of their products. Literature [12] divides online advertising into portal advertising and interactive advertising. Literature [13] classified online advertising as follows: banner advertising, button advertising, e-mail advertising, wallpaper advertising, sponsored advertising, competition and promotion advertising, interstitial advertising, interactive game advertising, commercial service advertising, full-screen advertising, banner advertising, picture-in-picture advertising, streaming advertising, interstitial advertising, instant popup advertising, mobile advertising, hover advertising, etc.

\section{Extension Neural Network Model}

3.1. The Concept of Matter Element. People and things are collectively called things. Things have various characteristics, and each characteristic can be characterized by a corresponding value. Therefore, the name, characteristics, and value of things are the basic elements to describe things, called the three elements of matter-element. Matter element is the basic element for formal description of matter. It is represented by an ordered triplet consisting of the name of the object, the feature (feature name for short), and the corresponding value, that is, the matter element (thing, feature name, and value).

The concept of matter element correctly reflects the relationship between the quality and quantity of things and the dynamics of things and can more closely describe the changing process of objective things. It studies things, characteristics, and corresponding values as a whole and provides a formal tool for solving contradictory problems by combining qualitative and quantitative methods.

3.2. Definition of Matter Element. We set the thing $N$, and it is about the value $v$ of the feature $c$, and the basic element of the thing can be described by the ordered triple $R=(N, c, V)$, referred to as the matter element. Since $V$ can be determined by $N$ and $c$, the matter element can also be expressed as [14]

$$
R=(N, c, V(N)) \text {. }
$$

The array with $n$ features and corresponding $n$ magnitudes is [15]

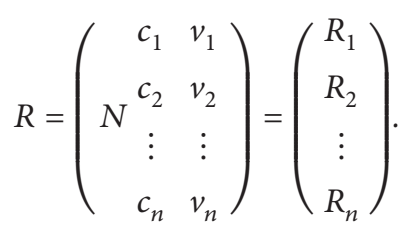

$R$ is an $n$-dimensional matter element, denoted as $R=(N$, $\left.c_{i}, V_{i}\right), i=1,2, \ldots, n$. Each dimensional matter element $R_{i}$ is called a divided matter element.

Extension sets are just a new concept in response to requirement. It could describe the mutual transformation between right and wrong and the degree to which things have certain properties.

$U$ is the universe of discourse, $u$ is any element in $U, k$ is a mapping from $U$ to the real domain $I$, and $T=\left(T_{U}, T_{k}, T_{u}\right)$ is a given transformation:

$\widetilde{E}(T)=\left\{\left(u, y, y^{\prime}\right) \mid u \in T_{U} U, y=k(u) \in T_{k}\left(T_{u} u\right) \in I\right\}$,

$g$ is an extension set on the universe $U, y=k(u)$ is the correlation function of $\widetilde{E}(T)$, and $y^{\prime}=T_{k} k\left(T_{u} u\right)$ is the extension function of $\widetilde{E}(T)$. Among them, $T_{U}, T_{k}, T_{u}$ are the transformation of the universe $U$, the correlation quasifunction $k$, and the element $u$, respectively [16].

Extension sets are based on set theory and described by correlation functions, which can be used as a tool to quantitatively describe the quantitative and qualitative changes of things. The value range of the correlation function is the entire real number axis. The value of the correlation function can describe not only the degree to which different things have the same nature, but also the degree to which things in mediation have certain properties, and it can also describe the degree of difference between different things with opposite properties. Algebraic expressions are used to express the correlation function of 
extension sets, which makes it possible to quantify the process of solving incompatible problems.

In the extension set, the concept of correlation function is established, and the concept of distance and place value is also established which serves as the basis for expanding the qualitative description to the quantitative description.

3.2.1. Definition of Distance. $x$ is a point on the real axis, $X_{0}=(a, b)$ is an interval on the real field [17]:

$$
\rho\left(x, X_{0}\right)=\left|x-\frac{a+b}{2}\right|-\frac{b-a}{2},
$$

is the distance between point $x$ and interval $X_{0}$. Among them, $(a, b)$ is either an open interval, a closed interval, or a half-open and half-closed interval.

3.2.2. Definition of Location. In practical problems, in addition to the positional relationship between points and intervals, the positional relationship between intervals and intervals and a point and two intervals must also be considered.

Then the bit value of point $x$ with respect to the interval set consisting of intervals $X_{0}$ and $X$ is specified as

$$
D\left(x, X_{0}, X\right)= \begin{cases}\rho(x, X)-\rho\left(x, X_{0}\right), & x \notin X_{0}, \\ -1, & x \in X_{0} .\end{cases}
$$

$D\left(x, X_{0}, X\right)$ is positional relationship between point $x$ and the interval set composed of $X_{0}$ and $X$, referred to as position value.

Describe the difference in the position of a point in the interval according to the difference of the value of the distance. The concept of distance describes the positional relationship between points and intervals, which makes people develop from "the same within a class" to a quantitative description with a degree of difference within the class.

On the basis of distance and position, the elementary correlation function is established [18]:

$$
K(x)=\frac{\rho\left(x, X_{0}\right)}{D\left(x, X_{0}, X\right)},
$$

and is used to calculate the degree of correlation between points and interval sets. Among them, $X_{0} \subset X$ and there is no public endpoint. The value of correlation function is $(-\infty,+\infty)$, and the above is to express the correlation function in the extension set, and the thing with "property $P$ " is extended from the qualitative description to the quantitative description of "the degree of property $P$. ."

For a certain evaluated object $N$, if there is an index SI that measures the pros and cons and the range of the required value is $X$, the allowable value range of the value is $X$. The establishment of the correlation function $K(n)$ represents the degree to which the object $N$ meets the requirements, which is called the correlation degree of $N$ with respect to SI.

$N$ is the correlation degree of SI on the measurement index $K(n)$; then [19]

$$
k=\left\{\begin{array}{cl}
\frac{K_{i}\left(N_{j}\right)}{\max _{x \in X_{0}} K_{i}(x)}, & K_{i}\left(N_{j}\right)>0, \\
\frac{K_{i}\left(N_{j}\right)}{\max _{x \notin X_{0}} K_{i}(x)}, & K_{i}\left(N_{j}\right)<0,
\end{array}\right.
$$

is called the standard relevance of $N$ to SI.

If a certain evaluated object is $N$, the measurement index set is $\mathrm{SI}=\{\mathrm{SI}, \mathrm{SI}, \ldots, \mathrm{SI}$,$\} , the normative correlation degree of$ $N$ to SI is $k_{i}(i=1,2, \ldots, n)$, the weight coefficient of SI is $a_{i}$, and $0 \leq a_{i} \leq 1 . a_{i}$ represents the relative importance of SI.

The extension evaluation method evaluates the research object from the perspective of feasibility and optimization and is a combination of qualitative and quantitative ones. It uses the extension of matter elements for qualitative calculations and uses extension set theory to perform quantitative calculations through correlation functions. Extension evaluation takes matter-element theory and extension mathematics as the theoretical basis and realizes the transformation of evaluation methods by establishing matter-element models.

In this paper, this method is applied to the evaluation and screening of schemes. The purpose of the screening is to remove the inferior and save the superior. The screening process is shown in Figure 1.

The criteria for evaluating the pros and cons of an object $N_{j}(j=1,2, \ldots, n)$ is $\mathrm{SI}_{1}, \mathrm{SI}_{2}, \ldots, \mathrm{SI}_{n}$.

There are majorities, and the weight coefficients are used to express the importance of each indicator. For the indicators that must be met, they are represented by the indicator input, and for other measurement indicators, values between $[0,1]$ are assigned. The weight coefficient is recorded as [20]

$$
\alpha=\left(\alpha_{1}, \alpha_{2}, \ldots, \alpha_{n}\right) .
$$

Since the selection of measurement indicators directly affects the evaluation results, the selection of measurement indicators must be cautious. Generally, indicators that meet the evaluation purpose, are representative, are easy to evaluate, and have relatively regular changes should be selected as the measurement indicators.

The selection of measurement conditions should pay attention to the following points:

(1) Purpose. We first attend the purpose of the evaluation and the evaluation object. The measurement conditions selected when evaluating different types of programs are different.

(2) Comprehensiveness. Goodness evaluation method is a comprehensive evaluation. In order to ensure this, the selection of measurement conditions must be representative. From the requirements of technology, economy, society, resources, environment, and development, select the most representative indicators that play an important role in achieving the goals of the plan. 


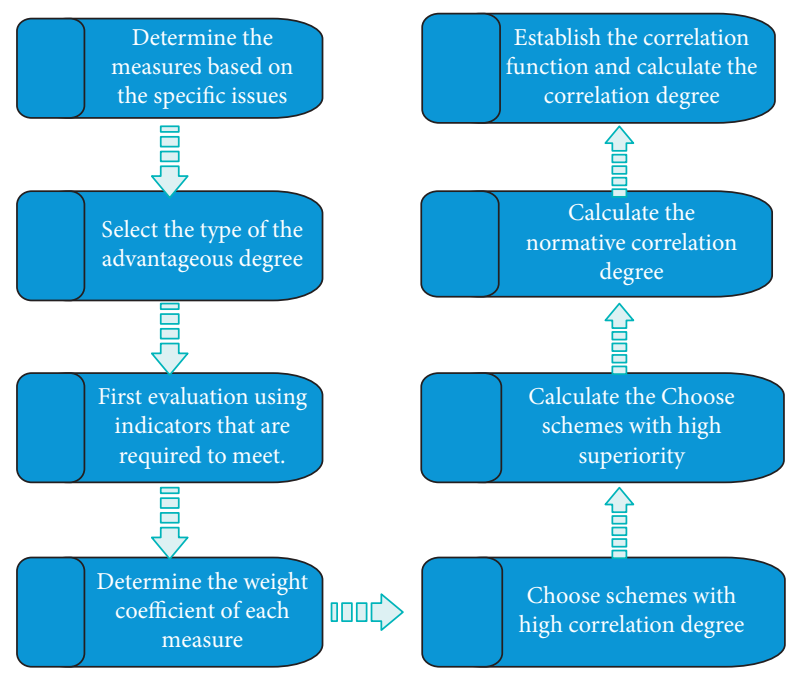

Figure 1: Basic flow of goodness evaluation method.

(3) Feasibility. The selected measurement conditions should be representative and usable for evaluation. Moreover, the data for the measurement conditions should be easy to obtain, and the data can be of high quality, truthfulness, and reliability.

(4) Stability. The selected measurement conditions should change more regularly.

Regarding the determination of the measurement condition SI, the following points should be paid attention to:

(1) It should be based on the actual situation of social as well as economic state and based on the spatial range data and historical data related to the evaluated object.

(2) It is necessary to pay attention to the development of social and economic state.

(3) The determination of the value range should have regulatory as well as management functions. The planned value of the national (regional, department) social and economic management can be considered as the boundary of the value range.

Among them, we set $\alpha_{i_{0}}=\Lambda$; then [21]

$$
\sum_{\substack{k=1 \\ k \neq i_{0}}}^{n} \alpha_{k}=1 .
$$

The size of the weight coefficient has a pivotal effect on the degree of goodness. Different weight coefficients cause a change in the order of the evaluated objects. Moreover, the analytic hierarchy process can be used to determine the relative importance order between the measurement indicators, thereby determining the weight coefficient.

After determining the weight coefficient of each measurement indicator, we use the indicators that must be met to filter and perform the following steps on the objects that have met the condition.
The measurement index set is $\mathrm{SI}=\left\{\mathrm{SI}_{1}, \mathrm{SI}_{2}, \ldots, \mathrm{SI}_{n}\right\}$, where $\mathrm{SI}_{i}=\left(c_{i}, V_{i}\right), i-1,2, \ldots, n$, and the weight coefficient is assigned as [22]

$$
\alpha=\left(\alpha_{1}, \alpha_{2}, \ldots, \alpha_{n}\right) .
$$

According to the requirements of each measurement index, the correlation function $K_{1}\left(x_{1}\right), K_{2}\left(x_{2}\right), \ldots, K_{n}\left(x_{n}\right)$ is established.

(1) If $V_{i}$ is a finite interval $X_{0 i}$ or an infinite interval, the algorithm takes the correlation function $K_{i}\left(x_{i}\right)$.

$$
K_{i}\left(x_{i}\right)=\frac{\rho\left(x, X_{0 i}\right)}{\left|X_{0 i}\right|}, \quad i=1,2, \ldots, n .
$$

(2) If $V$ uses $X$ and $X_{i}$ (XEX) to form an interval set description without a common end point, and the best point of this index is at point $x_{0 i}$, then the algorithm takes the elementary correlation function as

$$
K_{i}\left(x_{i}\right)=\frac{\rho\left(x_{i}, x_{0 i}, X_{0 i}\right)}{D\left(x_{i}, x_{0 i}, X_{0 i}\right)} .
$$

The correlation function of the object $N_{j}$ with respect to each measurement index $\mathrm{SI}_{i}$ is abbreviated as $K_{i}\left(x_{j}\right)$; then the correlation degree of each object $N_{1}, N_{2}, \ldots, N_{m}$ with respect to $\mathrm{SI}_{i}$ is [23]

$$
\begin{aligned}
K_{i} & =\left(K_{i}\left(N_{1}\right), K_{i}\left(N_{2}, \ldots, K_{i}\left(N_{m}\right)\right)\right), \quad i=1,2, \ldots, n, \\
k & = \begin{cases}\frac{K_{i}\left(N_{j}\right)}{\max _{x \in X_{0}} K_{i}(x)}, & K_{i}\left(N_{j}\right)>0 \\
\frac{K_{i}\left(N_{j}\right)}{\max _{x \notin X_{0}} K_{i}(x)}, & K_{i}\left(N_{j}\right)<0\end{cases} \\
i & =1,2, \ldots, j=1,2, \ldots, m .
\end{aligned}
$$

The canonical correlation degree of each object $N_{1}, N_{2}, \ldots, N_{m}$ with respect to $\mathrm{SI}_{i}$ is

$$
k_{i}=\left(k_{i 1}, k_{i 2}, \ldots, k_{i M}\right), \quad i=1,2, \ldots, n .
$$

The canonical correlation degree of object $N_{j}$ with respect to each measurement index $\mathrm{SI}_{1}, \mathrm{SI}_{2}, \ldots, \mathrm{SI}_{n}$ is [24]

$$
K\left(N_{j}\right)=\left[\begin{array}{c}
k_{1} \\
k_{2} \\
k_{3} \\
\vdots \\
k_{n}
\end{array}\right], \quad j=1,2, \ldots, m .
$$

According to the different requirements of actual problems, the superiority of object $N$ can be divided into three situations: 
(1) If in actual problems, the comprehensive relevance of all measurement indicators is required to be greater than 0 before the object $N$ is considered to meet the requirements, then the goodness is defined as

$$
C\left(N_{j}\right)=\sum_{i=1}^{m} \alpha_{i} k_{i}=\left(\alpha_{1}, \alpha_{2}, \ldots, \alpha_{n}\right)\left[\begin{array}{c}
k_{1 j} \\
k_{2 j} \\
\vdots \\
k_{n j}
\end{array}\right], \quad j=1,2, \ldots, m .
$$

(2) If in actual problems, as long as the comprehensive correlation degree of a certain measurement index is greater than 0 , it is considered that the object $N$ meets the requirements, then the goodness is defined as

$$
C\left(N_{j}\right)=\bigcup_{i=1}^{n} k_{i j}, \quad j=1,2, \ldots, m .
$$

(3) If in actual problems, the correlation degree of all measurement indicators is required to be greater than 0 before the object $N$ is considered to meet the requirements, then the degree of goodness is defined as

$$
C\left(N_{j}\right)=\bigcap_{i=1}^{n} k_{i j}, \quad j=1,2, \ldots, m
$$

According to actual problems, we first evaluate the evaluation object with "indicators that must not be satisfied." For all objects that meet the requirements, we use one of the above three kinds of goodness to calculate its goodness and compare the goodness of $N$. If

$$
C\left(N_{0}\right)=\max _{j=\{1,2, \ldots, m\}}\left\{C\left(N_{j}\right)\right\},
$$

then object $N_{0}$ is better.

The essence of the extensional neural network that can analyze things qualitatively and evenly is derived from the quantitative analysis ability of the correlation function. However, extenics is single-threaded, and there is no multithreaded, parallel operation and computing power. Neural networks can overcome this shortcoming of extenics. Therefore, extenics and neural networks are combined to learn from each other. On the one hand, visualization technology is used to construct a new neural network structure. On the other hand, the learning mechanism of the network is combined with the extension matter element, and the sample data is learned and trained on this basis to achieve the purpose of improving the learning efficiency and the correctness of the classification. The extension neural network is shown in Figure 2.

It belongs to a two-layer structure, including an input layer and an output layer, with the connection weight of the input neuron and the output neuron. Each node in the input layer is a different feature of the multidimensional matter element. The number of neurons in the input layer depends on the number of input parameter vectors. Each neuron in

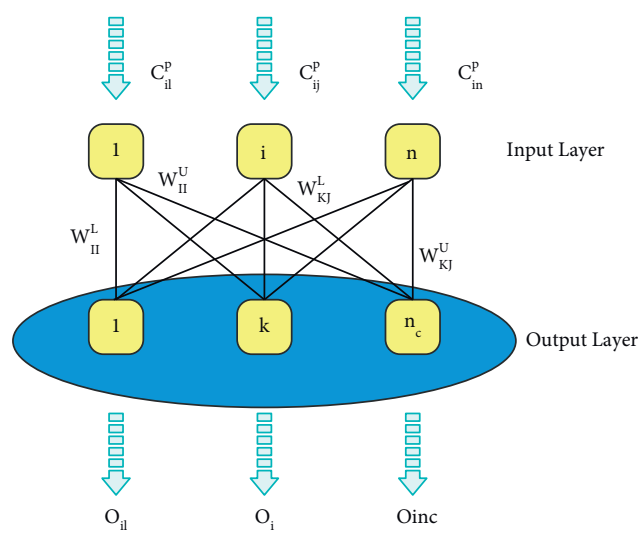

FIGURE 2: Extension neural network model structure.

the input layer and each neuron in the output layer are bidirectionally connected with weights. The basic unit of connection is the minimum value of the feature vector field and the maximum value of the feature vector.

\section{New Media Advertising Communication Analysis Model Based on Extension into the Network}

The consumer decision-making process gives a good description of the correlation between consumers and brands. This process also describes in more detail the process of consumers from having a purchase demand to generating a purchase action to achieving mutual trust, and it also studies how to influence consumer behavior in this process. The consumer decision-making process has also gone through six stages, which are mainly divided into consideration, evaluation, purchase, experience, mutual fans, and mutual trust, as shown in Figure 3.

Based on the theory of consumer decision-making process, the author also summarized the structure of the communication mode under mobile advertising from the perspective of consumer psychology based on the reality under the background of the mobile Internet era (Figure 4).

The advertising communication model established in this paper is different from the general advertising communication model. It combines complex network theory and advertising communication theory to construct an advertising communication model that can quantify the effect of communication. The channels of advertising communication in this paper are divided into two types: mass communication and interpersonal communication. Moreover, this paper proposes a two-layer network topology structure of the advertising dissemination network, as shown in Figure 5.

From a logical point of view, it is easier to understand the two-layer structure of the advertising dissemination network. As shown in Figure 5, the first-level interpersonal communication network reflects the relationship between user nodes. There are friend relationships between edgeconnected nodes, and both parties can transmit information. Therefore, for user nodes, it is important for 


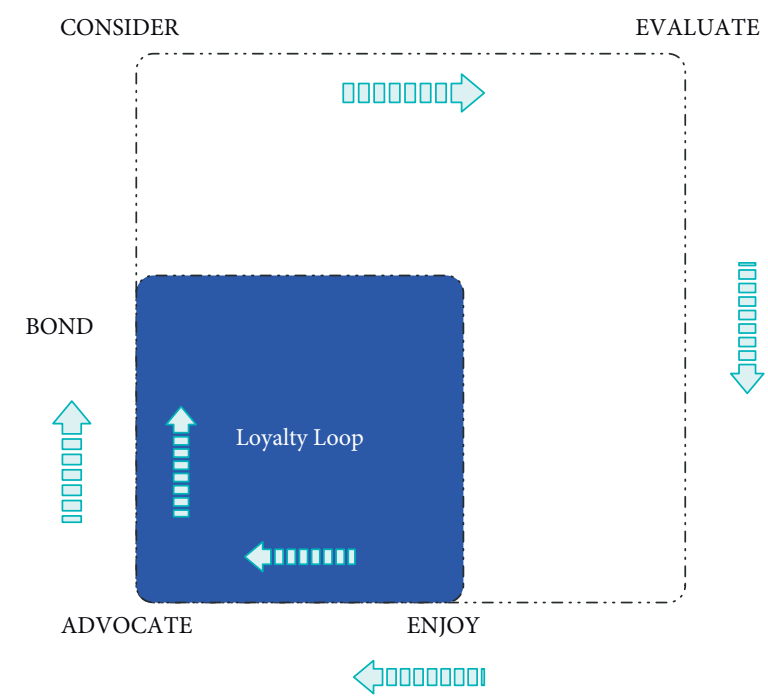

Figure 3: Consumer decision-making process.

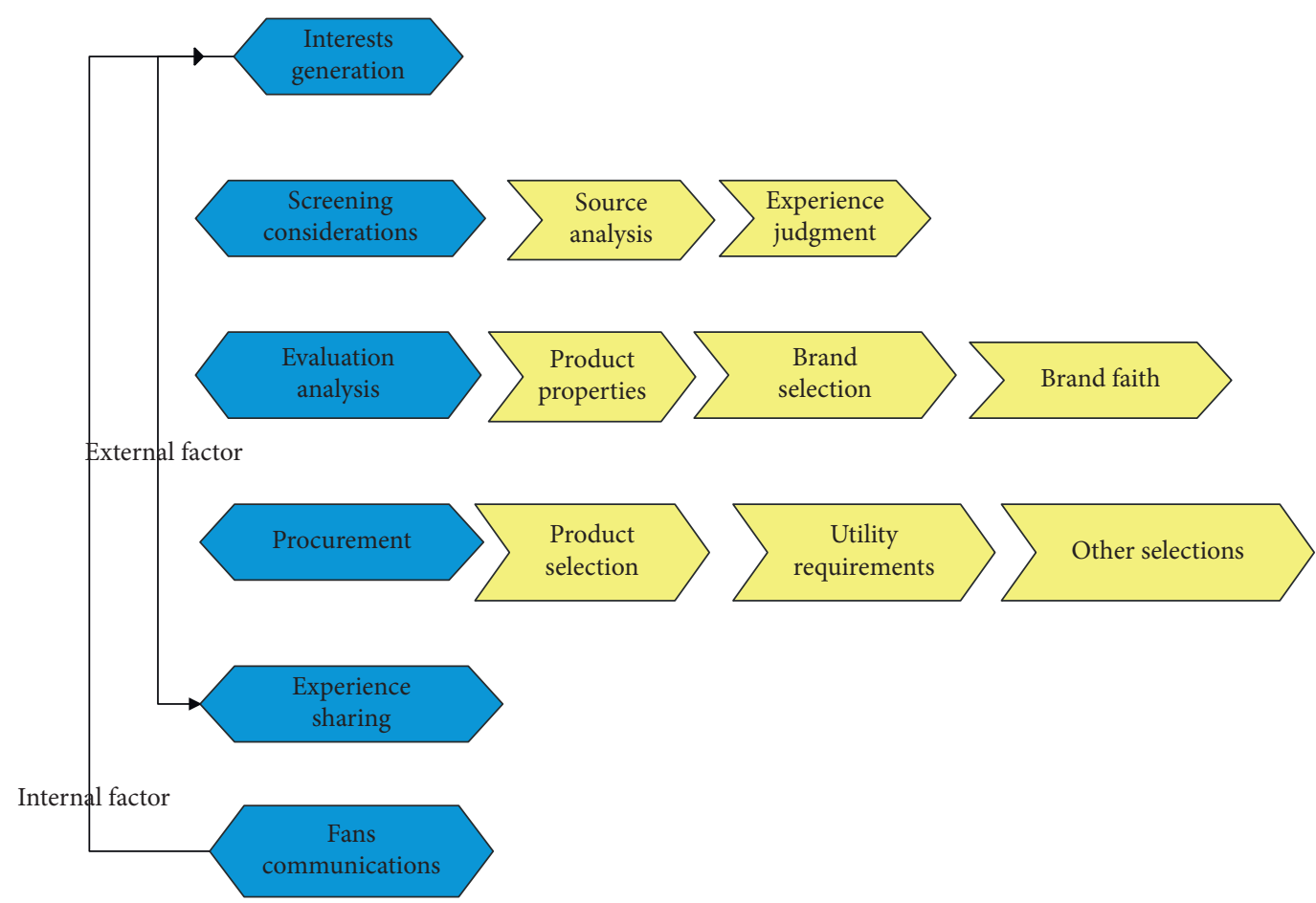

FIGURE 4: Improved model of mobile advertising communication mode.

advertising. Information attitudes and behaviors are affected by their friends' nodes; the second-tier mass communication network is a network composed of mass communication media used in advertising, and the mass communication network includes several specific media networks, each of which is specific The media network refers to the network composed of user nodes owned by the media and reflects the relationship between the user nodes and the media.

The establishment of advertising communication network is the necessary foundation and prerequisite for the follow-up simulation to proceed smoothly. Next, the
Nanjing area will be used as the target of advertising, and the two-layer network model of advertising will be used to construct an advertising communication network model. First, build the first layer of interpersonal network. Since the first-level network reflects the interpersonal relationship between people, it is necessary to build an interpersonal network. From the well-known phenomenon of "six degrees of separation," each node in the interpersonal network can also be connected indirectly through several individual nodes in the network; that is, the interpersonal network has obvious small world characteristics, so randomization will be used in this article. The method of 


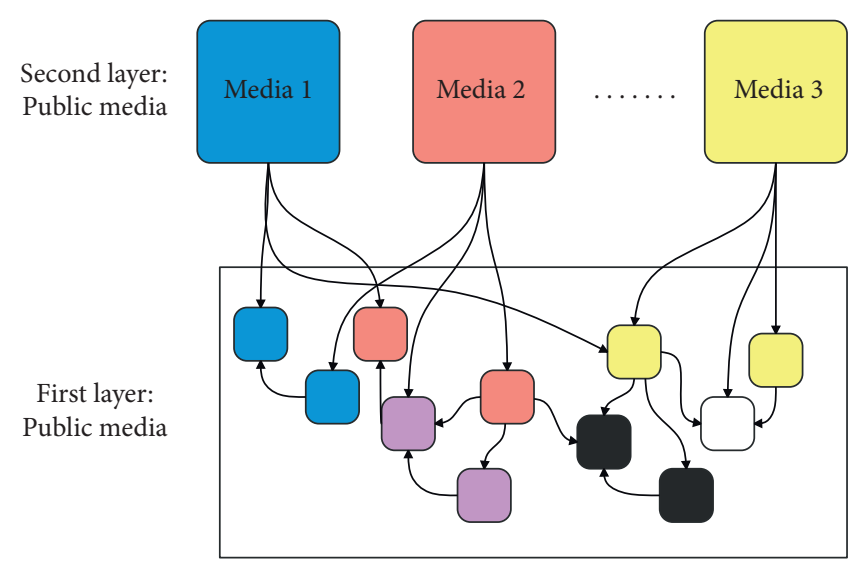

FIGURE 5: Structure diagram of advertising dissemination network.

adding edges constructs a NW small world network as the interpersonal network in the advertising communication network, that is, the first-layer network of advertising communication.

Generally, the scale of the interpersonal communication network is set to 1000 , and the node degree distribution and clustering coefficient of the interpersonal network constructed according to the NW network construction method are shown in Figures 6 and 7, respectively.

The number of user nodes when advertisement propagation reaches a steady state is represented by a table as shown in Table 1.

It can be seen from Table 1 that when the propagation process reaches a stable state, the number of nodes in the final unknown state is the least, and television media is the least, followed by newspapers, networks, radio stations, and magazines. From the perspective of the final purchase status alone, television media is the most, followed by newspapers, Internet, radio, and magazines. In terms of the number of neglected states alone, newspaper media is the largest, followed by the Internet, TV, magazines, and radio. After knowing the situation of their respective advertisements, the comparative changes of their advertisements' spread are shown in Figure 8.

Through the above analysis, the effect of the model proposed in this paper is verified, multiple sets of advertisements are obtained through the Internet, and the effect of the model of this paper is verified. First, the analysis effect of the model of this paper on the advertising data is verified, and the results shown in Table 2 and Figure 9 below are obtained.

From the above analysis, it is verified that the new media advertising communication analysis model based on extension network can play a certain role in advertising data analysis. On this basis, this paper conducts the

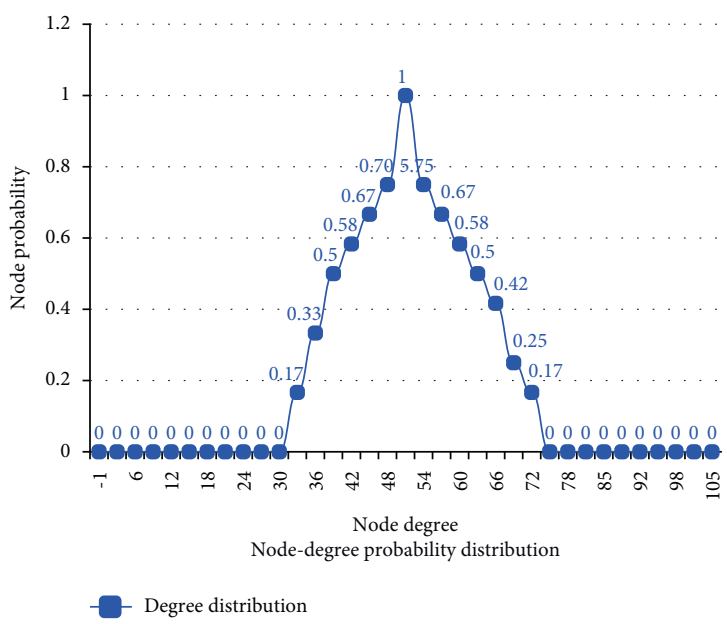

FIGURE 6: Probability distribution of network node degree.

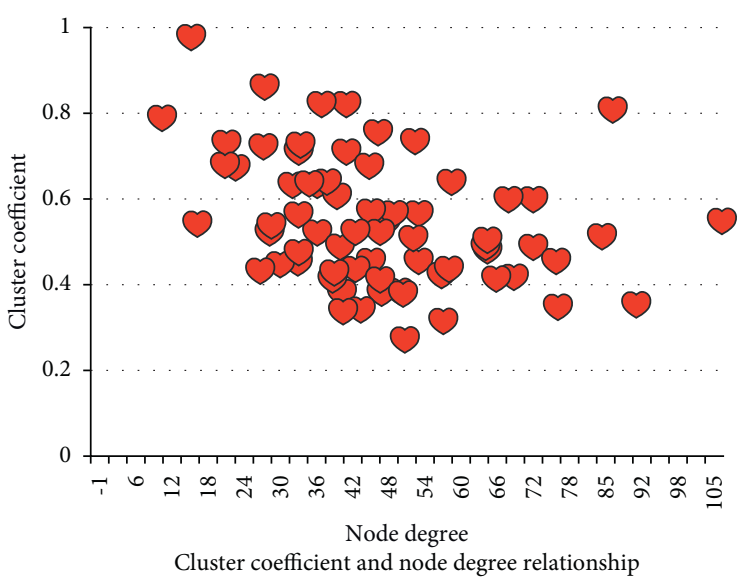

FIGURE 7: The relationship between network clustering coefficient and node degree. 
TABle 1: Proportion of nodes in various states when the propagation reaches a steady state.

\begin{tabular}{lccccc}
\hline & Unknown state & Known state & Desired state & Purchase state & Ignore state \\
\hline Magazine & 0.770 & 0.000 & 0.000 & 0.160 & 0.250 \\
Radio station & 0.700 & 0.000 & 0.000 & 0.440 & 0.050 \\
The Internet & 0.450 & 0.000 & 0.000 & 0.620 & 0.110 \\
Newspaper & 0.240 & 0.000 & 0.000 & 0.750 & 0.150 \\
Television & 0.140 & 0.000 & 0.000 & 0.110 \\
\hline
\end{tabular}

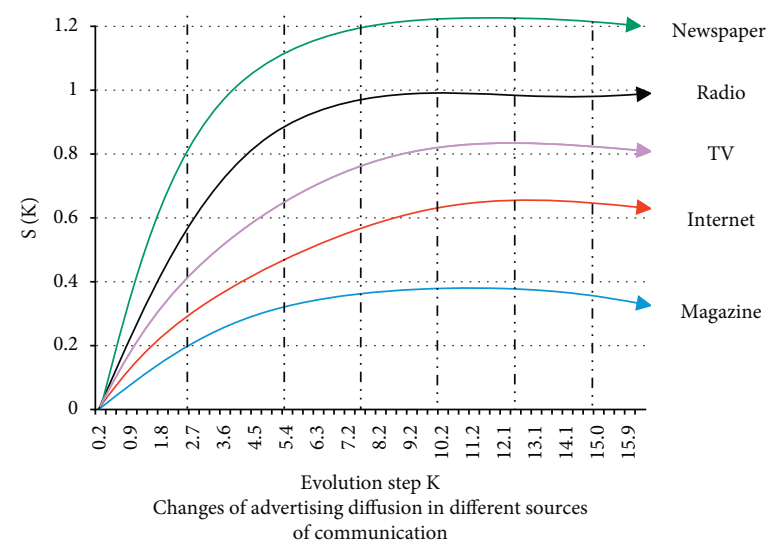

Figure 8: Changes in the diffusion degree $s(k)$.

TABLE 2: The analysis effect of the model on advertising data.

\begin{tabular}{lccccc}
\hline Number & Advertising data analysis & Number & Advertising data analysis & Number & Advertising data analysis \\
\hline 1 & 79.75 & 11 & 84.99 & 21 & 92.31 \\
2 & 88.38 & 12 & 79.95 & 22 & 86.31 \\
3 & 85.78 & 13 & 85.75 & 23 & 84.67 \\
4 & 84.66 & 14 & 90.10 & 24 & 80.06 \\
5 & 87.40 & 15 & 87.34 & 26 & 83.38 \\
6 & 81.86 & 16 & 88.44 & 27 & 80.30 \\
7 & 87.74 & 18 & 79.99 & 28 & 80.80 \\
8 & 90.40 & 19 & 87.51 & 29 & 81.35 \\
9 & 81.94 & 20 & 87.73 & 30 & 91.95 \\
10 & 92.27 & & & \\
\hline
\end{tabular}

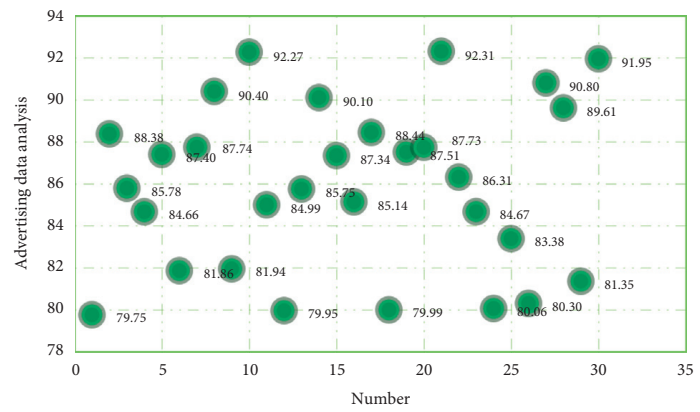

Figure 9: Statistical diagram of advertising data analysis test.

performance verification of the new media advertising communication analysis, and the expert evaluation method is used to verify the results shown in Table 3 and Figure 10 below.
From the above experimental verification, it can be seen that the new media advertising communication analysis model based on the extension of the network proposed in this paper meets the new media advertising communication analysis effect. 
TABle 3: Performance verification of new media advertising communication analysis.

\begin{tabular}{lccccc}
\hline Number & Communication effect analysis & Number & Communication effect analysis & Number & Communication effect analysis \\
\hline 1 & 78.16 & 11 & 76.96 & 21 & 85.91 \\
2 & 73.08 & 12 & 82.13 & 22 & 85.67 \\
3 & 87.20 & 13 & 76.68 & 23 & 88.62 \\
4 & 81.40 & 14 & 83.71 & 24 & 73.60 \\
5 & 77.14 & 15 & 76.92 & 25 & 80.63 \\
6 & 76.21 & 16 & 77.67 & 26 & 80.53 \\
7 & 73.80 & 17 & 88.90 & 27 & 88.12 \\
8 & 77.57 & 18 & 78.24 & 28 & 78.42 \\
9 & 87.52 & 19 & 72.63 & 30 & 74.30 \\
10 & 75.83 & 20 & 30 & 88.07 \\
\hline
\end{tabular}

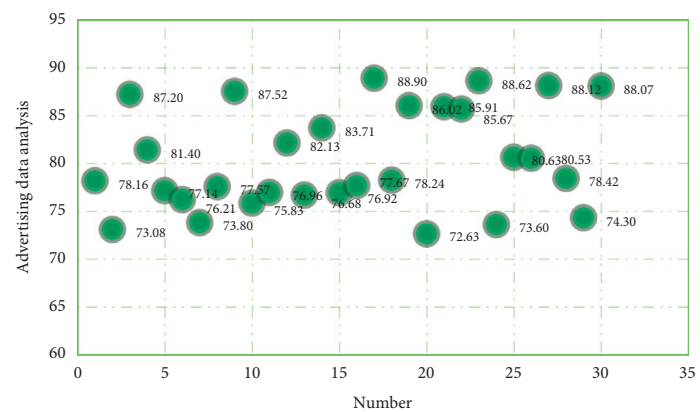

Figure 10: Advertising communication performance analysis.

\section{Conclusion}

The media is the platform and support for advertising and dissemination, and the relationship between advertising and the media is close and inseparable. A certain understanding of media, especially emerging digital media and communication knowledge, is a necessary foundation for advertising activities. The development of communication technology has caused media competition to become fierce. Although mass communication media occupies a large market share and competitiveness, the lack of communication characteristics of traditional media makes the communication effect unsatisfactory. Network media has the new characteristics of media communication, such as large amount of information, diverse forms, being rapid and timely, global communication, easy copying, easy retrieval, freedom, and interaction, which undoubtedly fill the deficiencies of traditional media. On the other hand, with the increasingly obvious trend of consumer market segmentation and increasingly fierce competition in the advertising market, these factors have provided a hotbed for rapid development of online advertising as the main pillar of the advertising industry. This thesis combines the scalable neural network to construct the new media advertising communication analysis model and conducts research on the new media advertising communication analysis. The experimental verification shows that the new media advertising communication analysis model based on the extension of the network proposed in this paper meets the new media advertising communication analysis effect.

\section{Data Availability}

The data used to support the findings of this study are available from the corresponding author upon request.

\section{Conflicts of Interest}

The authors declare that there are no conflicts of interest.

\section{Acknowledgments}

This work in this article was supported by North China University of Technology.

\section{References}

[1] F. Guo, G. Ye, L. Hudders, W. Lv, M. Li, and V. G. Duffy, "Product placement in mass media: a review and bibliometric analysis," Journal of Advertising, vol. 48, no. 2, pp. 215-231, 2019.

[2] A. Yadi Yaakop, S. A. Ismail, S. Aishah Ismail, and Z. Zainal Ariffin, "Breaking through clutter: analysis of mobile political advertising in Malaysia," International Journal of Social Science and Humanities, vol. 9, no. 2, pp. 26-30, 2019.

[3] U. U. Akpan, "Print media management and ethical advertising under r," Journal of Media Management and Entrepreneurship, vol. 3, no. 1, pp. 1-11, 2021.

[4] A. R. Condeza Dall'Orso, P. Matus Lobos, and E. Vergara Leighton, "Stereotypes and sexualization of girls and adolescent girls in Chilean advertising: a case study," Tripod, vol. 50, no. 50, pp. 187-204, 2021.

[5] C. Kolo and F. Haumer, "Social media celebrities as influencers in brand communication: an empirical study on influencer content, its advertising relevance and audience expectations," Journal of Digital and Social Media Marketing, vol. 6, no. 3, pp. 273-282, 2018.

[6] R. L. Gruner, A. Vomberg, C. Homburg, and B. A. Lukas, "Supporting new product launches with social media communication and online advertising: sales volume and profit implications," Journal of Product Innovation Management, vol. 36, no. 2, pp. 172-195, 2019.

[7] H. Li, "Visual communication design of digital media in digital advertising," Journal of Contemporary Educational Research, vol. 5, no. 7, pp. 36-39, 2021.

[8] Y. Wang and E. N. Remchukova, "Development of the advertising specialty in higher education in Russia and China," RUDN Journal of Psychology and Pedagogics, vol. 18, no. 3, pp. 532-554, 2021. 
[9] H. A. M. Voorveld, "Brand communication in social media: a research agenda," Journal of Advertising, vol. 48, no. 1, pp. 14-26, 2019.

[10] E. Pancaningrum and W. A. Rahayu, "The effectiveness of Facebook as an advertising strategic method using EPIC: a case study of Mie Jupe Jombang," Chinese Business Review, vol. 16, no. 7, pp. 309-315, 2017.

[11] H. Li, "Special section introduction: artificial intelligence and advertising," Journal of Advertising, vol. 48, no. 4, pp. 333-337, 2019.

[12] T. Arora, B. Agarwal, and A. Kumar, "A study of millennials's preferences for social media advertising in Delhi NCR," Indian Journal of Marketing, vol. 49, no. 10, pp. 34-51, 2018.

[13] S. Ali, "Women objectification and advertising: an analysis of sexually objectified portrayal of women in television advertising in Pakistan," Global Media Journal, vol. 16, no. 31, pp. 1-9, 2018.

[14] T. Arora and B. Agarwal, "An empirical study on determining the effectiveness of social media advertising," International Journal of E-Business Research, vol. 16, no. 2, pp. 47-68, 2020.

[15] A. Ujică and R. Băbuţ, "Female stereotypes in Romanian advertising: an interpretative content analysis," Studia Universitatis Babes-Bolyai Oeconomica, vol. 66, no. 2, pp. 25-37, 2021.

[16] E. N. Malyuga, E. V. Ponomarenko, and A. V. Minayeva, "Stylistic devices as means of forming discursive features of advertising minitexts (exemplified by English economic and political media sources)," Vestnik of Samara University. History, Pedagogics, Philology, vol. 26, no. 4, pp. 82-87, 2020.

[17] D. Datta and A. K. Choudhury, "Economics OF health care service sector related public service outdoor media advertising IN Tripura, India," International Journal on Recent Trends in Business and Tourism, vol. 3, no. 3, pp. 35-48, 2019.

[18] M. Guardino and D. Snyder, "The capitalist advertising and marketing complex and the US social order: a political-materialist analysis," New Political Science, vol. 39, no. 4, pp. 588-608, 2017.

[19] H. Jin and F. Yang, "A strategic study on customer engagement improvement from the perspective of short video advertising: take douyin as an example," International Journal of Engineering and Management Research, vol. 4, no. 3, pp. 6-8, 2020.

[20] T. Dummanonda and C. Nuangjamnong, "The influence of social media advertising value on consumer behavior in renting apartment rooms in bangkok, Thailand," International Research E-Journal on Business and Economics, vol. 6, no. 1, pp. 13-27, 2021.

[21] B. Yoosefy, H. Honari, A. Ghobadi Yeganeh, and V. N. Palangard, "The effect of sport fandom and general attitude towards advertising on the credibility of sports advertising," Communication Management in Sport Media, vol. 7, no. 3, pp. 33-42, 2020.

[22] A. Yazdanparast, I. Naderi, N. Spears, and R. O. Fabrize, "Advertising and pseudo-culture," Journal of Macromarketing, vol. 38, no. 2, pp. 185-205, 2018.

[23] R. Winks and K. Cresen, "Impact OF language frames IN advertising effectiveness," International Journal of Linguistics, vol. 1, no. 1, pp. 28-33, 2021.

[24] X. Yu and T. Natori, "Scientific mapping for advertising in recent decades: a citespace bibliometric analysis," International Journal of Japan Association for Management Systems, vol. 12, no. 1, pp. 103-110, 2020. 